\title{
Challenges in the coordination of children's healthcare
}

Rosane Meire Munhak da Silva ${ }^{1}$

Reinaldo Antônio da Silva Sobrinho ${ }^{1}$

Eliane Tatsch Neves ${ }^{1}$

Beatriz Rosana Gonçalves de Oliveira Toso ${ }^{1}$

Cláudia Silveira Viera ${ }^{1}$

${ }^{1}$ Universidade Estadual do Oeste do Paraná. Av. Tarquínio Joslin dos Santos 1300, Polo Universitário. 85870-650 Foz do Iguaçu PR Brasil.

zanem2010@hotmail.com
Abstract This is a qualitative survey with a hermeneutic-dialectic frame of reference, designed to identify how parents and caregivers see the attribute 'coordination' in children's healthcare, in terms of resolving problems in children's health. The interview was held with 16 people responsible for care of children under one year of age, served in Emergency Care Units of a municipality in the south of Brazil, in 2010. With the thematic analysis, the central category was identified as: Effects and results of fragile coordination in Children's Primary Health Care, with the following themes: Divergences between different health units in the organization of care; functional barriers and delays obstructing access to technologies; absence of effective communication; absence of medical transport; need for healthcare on an individual basis; and coordination involving management of healthcare. It was concluded that the absence of coordination results in the absence of a solution-based approach in healthcare for children under one year old, showing gaps in the organization of the services and in health management, since communication, access to technologies, referral and counter-referral systems, and secure transport become essential for organizing primary care services and offering fully rounded care to the child. Key words Primary Health Care, Care of children, Health services, Pediatric nursing 


\section{Introduction}

Social transformations have led to high indices of infant mortality all over the world, and initial attempts by those in government have not been fully efficacious in changing this scenario. Concrete changes in infant mortality indices have only been perceived when the situation of children has been understood and investments made in wide-ranging public policies, which among other factors involve socio-economic variables ${ }^{1}$.

Although there has been a significant reduction in infant mortality in Brazil - to 16 deaths per thousand live births in 2011, thus reaching one of the targets of the Millennium Development Goals (MDGs) ${ }^{2}$, great problems have remained, with high mortality in the neonatal period, caused by perinatal complications and premature birth - and also the possibility that sensitive primary health care actions could reduce these deaths by $60 \%{ }^{1,3,4}$. Further factors adverse to children's health have been avoidable illnesses, and avoidable hospital admissions, which show the fragility of the primary healthcare services in developing countries, such as Brazil 5 .

The concept of primary healthcare refers to a group of assistance, equitably distributed to the population, aiming to resolve common problems by the supply of preventive, curative, rehabilitating or palliative actions. To put them into effect, it is essential that a group of attributes should be present, in a manner that is mutually coordinated: access, long-term care, integration and coordination ${ }^{6}$.

The attribute of coordination, which is the context of this study, seeks to ensure continuity of healthcare, by recognizing problems that need to be accompanied in other parts of the healthcare network ${ }^{3}$. Such coordination makes available information on problems that people are suffering from, and also the technologies related to the care that they demand ${ }^{6,7}$. For this, effective communication mechanisms need to exist between the various points of care ${ }^{3,6,7}$; associated with access to the services that are necessary for resolving health problems, and the principle of integral care as an organizer of the healthcare system, including elements that are essential for care, namely: a) a faculty for movement and adaptation, construction of care as it is lived; b) interaction, establishment of relationships; c) awareness of and respect for the other, construction and reconstruction of identity based on the family and through social interactions; d) plasticity, the ability and capability to transform; e) a plan - the factor that creates care; f) desire, causing plans to emerge from actions by free choice, increasing the interest and need for health practices; g) temporality, an aspect of being cared for; h) non-causality, training in humanity through cognitive cause-effect aspects; and i) responsibility, self-comprehension and formative construction of the human being ${ }^{8}$.

Guided by these considerations, the aim of this article is to identify the attribute 'coordination' in primary healthcare, in the perception of parents/caregivers, for resolution of health problems in children less than one year old, attended in Emergency Care Units (Unidades de Pronto Atendimento or UPAs), in a municipality of the South of Brazil.

\section{Method}

This is a survey with a qualitative approach based on the hermeneutic-dialectic methodology as reference frame. The term hermeneutics refers to interpretation and significance of concepts, the comprehensive understanding stimulated by the practical interest of social groups $s^{9,10}$ : a solid experience of interactions. And it is not limited to a traditional logical repetition of thinking, but seeks to expand thinking through comprehension and interpretation ${ }^{11}$.

This study is an excerpt from a master's degree dissertation, that was built on the basis of a two-centered project called 'Characterization of children under the age of five served in emergency care units in two municipalities of the South of Brazil', financed by the CNPq. Thus, the subjects were selected based on the sample of that project, comprising 642 children served by the Emergency Care Units of Cascavel, in the Brazilian state of Paraná (PR), in 2010. Among this total, 16 families with children less than one year old were selected, spread out over the year of 2010. Collection of data took place in the first half of 2012, beginning in the sectors holding the files of the Emergency Care Units, to arrive at clinical characterization of the children. The next step was in the homes of the subjects, for the research on the principal object of the survey, namely the degree of solution of problems provided by children's healthcare, centering on the attribute 'coordination' as experienced in primary healthcare. The families were contacted, and if interest was shown in taking part in the survey, then, following acceptance, the interview was scheduled to be held in the subjects' own homes, 
which were in the urban area of the municipality. For this phase, three collection techniques were used: interviews in the home, 'spoken maps' and semi-structured interviews.

Interviews were closed as soon as the data had generated a construct, providing enough arguments for logical comprehension of the events, responding to the objective of the study ${ }^{10}$.

The results were structured by thematic analysis built up in a horizontal map, and, after repeated readings, the significant structures and the categorization by subject were arrived $a^{12}$. The analysis was anchored on the reference points relating to the attribute coordination in primary healthcare ${ }^{6}$, and elements of integrated care ${ }^{8}$.

This study was approved by the Research Ethics Committee of the State University of the West of Paraná State (Universidade Estadual do Oeste do Paraná), in accordance with Resolution $466 / 2012^{13}$, of the Brazilian National Council for Health and Human Research. The participants signed the Informed Consent Form. Fragments of interviews presented were identified in the text by the letter $S$ (subject), followed by the ordinal number 1 to 16 , ensuring anonymity for the participants.

\section{Results}

The central thematic category was identified as: Effects and results of fragile coordination in children's primary healthcare, incorporating the following subjects: Differences in organization of care between health units; functional barriers and delay impeding access to technologies for healthcare; absence of effective communication; absence of medical transport; the aim to achieve healthcare for the individual; and coordination involving management of healthcare.

\section{Effects and results of fragile coordination in children's primary healthcare}

One of the fragilities in the coordination of primary healthcare was understood to be the entry barrier to these services, indicated by the subjects, represented by the difficulties in scheduling medical appointments, because each service organizes its daily dynamic according to its own needs, so that differences of organization emerge between health units, and care protocols are not standardized.

In the health post of our district of the city it's difficult to get a vacancy. [...] the doctor is on hol- iday. [...] there are two areas [Unidade de Saúde da Familia (USF) - Family Health Unit], [...] in the other area the doctor can't see us. So we always have to be looking for another health center or go to the PAC [Posto de Atendimento ContinuadoContinued Healthcare Post]. In the health center of the closest adjoining district, we go on Monday morning and make an appointment for sometime in the whole week [...] (S6).

We have to go in the small hours. We have to wait in line, around just after five o'clock in the morning - if you arrive later, the tickets run out and you don't get one [...] you have to be in line every day, you never get the appointment on the same day, it's always set for the next day [...] (S10).

Services that have Primary Healthcare System (APS) as their healthcare coordinators have the capacity to identify and solve problems. They are considered as preferential points of entry to the health system and as entities organizing care, to ensure that families are provided with integrated care, and real solutions. However, as a reality taking place in fact, the Emergency Care Units (UPAs) were considered to be priority when parents/caregivers seek care for children, illustrated in Figure 1. The complicated flows and itineraries for families, who have to remain in interminable waiting lines, and the hardly attentive care given by unqualified health professionals, shows the non-existence of coordination and, consequently, the lack of capacity to provide solutions in children's healthcare.

[...] if I get [an appointment ticket] for three of my children, I have to take two people with me, because they [the receptionists] don't allow me to take one ticket for the three. [...] or I have to go to

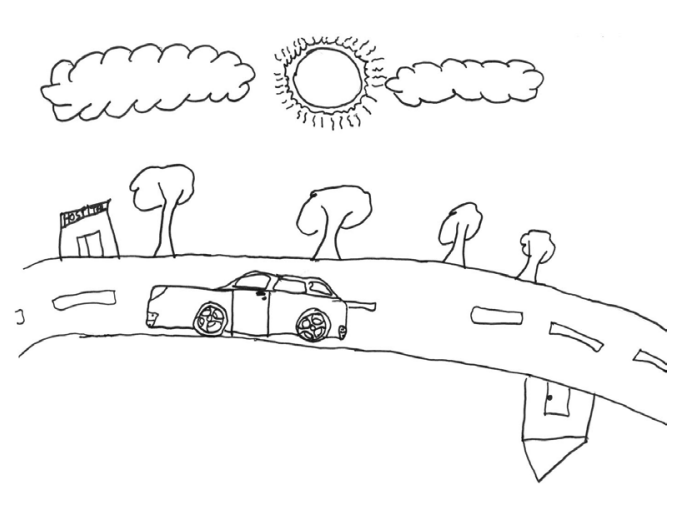

Figure 1. Spoken Map produced by S8, Cascavel, Parana, 2012. 
the end of the line. [...] this means I suffer, because I have five children [...] (S12).

When it comes to the return visits, some of the services organize themselves so that families do not have to face the whole process over again, while others impose obstacles.

[...] the doctor herself leaves the appointment already scheduled. [...] we arrive with the test results and we are attended immediately [...] (S4).

You have to do it all over again [...]. The whole of the same rush and bother, to reschedule it all for the second time (S6).

After medical consultations have been scheduled, the waiting time before being attended was also unequal between the units.

There are times that it takes one hour, two hours, it depends a lot (S8).

In the health post of the next-door district [...] it was really quick, didn't take more than 15 minutes [...] (S10).

The data show that the access to health services involves abandonment of barriers, principally functional barriers, which are related to the way in which the services are organized: these related to the attribute coordination. In the reality taking place in fact, one sees functional barriers and delays impeding the access to the technologies for healthcare.

[...] the pediatrician ordered an $x$-ray, I had to go and get it authorized at the center and wait, I think it was five or six days. Then afterwards I had to set the appointment here at hospital $X$ and wait there, too. After doing it, I had to wait to get the results. [...] I think it needs to be faster, not to have all this delay, all this coming and going [...] (S10).

Health services that aim to provide the attribute coordination over their whole extension need to include in their practices the use of technologies, categorized as hard, soft-hard or soft, and in view of the need for hard technologies, as a way of contributing to children's healthcare, these services should be functional to ensure users get directed to them, through the use of pre-established protocols.

At some moments the functional obstacles do not prevent access, but can make it more difficult to use the group of services and technologies that are necessary, due to changes in the dynamics of the services without the community being informed.

[...] I went and scheduled the ophthalmologist, I waited a year, my ticket was finally issued and then he [the doctor] simply said: 'Oh, you have to have a referral'. [...] then in the health post [...] they [the receptionists] said come back tomorrow morning, we'll see if we can fix it for you [...]. So I said: 'How do you manage a consultation for me without my having a referral?' They said [the receptionists]: 'Previously one didn't need one, now it's only possible with a referral [...]' (S13).

The slowness of services compromises access to capacity to provide actual solutions in healthcare. Services that have an effective coordination, orienting care along all of their points and throughout the life of the community, recognize the problems of families and articulate the networks of support and attention so that flows take place quickly, without prejudicing the care. This was perceived by the caregivers.

Actually getting an appointment with a specialist is a war: my cousin has been waiting in line for four years to get an appointment with a psychiatrist, and hasn't yet succeeded [...] (S6).

[...] tomography, we know it's expensive [...] it's unacceptable to have to do it only a year from now. Two years to do an exam like that, I think that's offensive [...] (S4).

Faced with the slowness of services, families find the only viable solution is to carry out privately-paid tests and consultations, although often they do not have the financial situation for this.

[...] the tests - I didn't do them through the health post, because if you wait you'll have 10 children before they actually happen. It just takes too long, so we paid for everything [...] (S3).

To achieve an integrated and solution-providing approach, communication between the user and the health team is essential. Thus, this communication should exist between community services and the levels of healthcare, including in relation to the families that use the services. In this study deficiencies were found in this aspect, since the theme itself has doubts relating to the functioning of the services when transmitting the information, thus giving clear evidence of the absence of effective communication.

[...] I asked 'Is there a doctor?' and she [the health agent] said: "You know something? I don't know - I'll call you'. That call never came [...]. Now I asked when the doctor would come back [...], and so far no-one has called me [...]. I have to go there, ask, get an answer, figure it out and organize it myself [...] (S6).

There was also evidence of deficiencies in information on the workings of Basic Healthcare Units (Unidades Básicas de Saúde - UBS), causing blockages in children's healthcare.

They [health professionals] didn't tell me. I collected the sample, after two days I got the result and took it to the doctor. When I arrived at the 
healthcare unit, [...] she [receptionist] said: 'They didn't say anything about its arriving directly by internet? [...]' (S12).

As well as the acute conditions referred to above, there was a lack of communication and information relating to actions working in favor of health and continuing care.

[...] I didn't know that I had to file the request for tubal sterilization at the beginning [of the pregnancy] [...], I thought I could do that in the final days. The doctor never told me that [...] [caregiver, mother of five children, who would like to have had a tubal ligation] (S12).

Also, ensuring full integral care for families and their components requires a commitment of the health services to provide efficient and continuous services, which may go beyond the Primary Healthcare service. Healthcare takes place not only inside health units, but at moments of referral to specialized consultants or for tests. For this, it is essential that the services should have adequate transport that guarantees people full care and safety. According to the caregivers, the presence of medical transport that we refer to was not provided.

[...] yesterday a mother arrived [at a Basic Healthcare Unit] with a child who I think, had fallen off a bicycle, [...] they told the mother to take him to the PAC [Posto de Atendimento Continuado - Continued Healthcare Post] or to the small health post in the neighboring district. She [the mother] had no way to go there. She was desperate to get there and had to find some way to do so. The child was bleeding, and she had a really small baby on her arm - and even so ... (S16).

Although they do not carry out the necessary care for the child, innumerable services do not take responsibility for this, and abandon families when their children are ill, asking them to seek care in other services, without any support through the referral system, so that people are left to seek healthcare on their own.

They told me to go to a PAC, but they didn't give me any referral, ever. (S15)

Looking at this in terms of the attribute coordination, even being prevented from providing medical consultations, the health services could still accept and take responsibility for their users. In situations where there are no alternatives other than a medical consultation, they could refer their users to urgent and emergency services, through a system of reference and counter-reference, and secure transport. This conception, in counterpart to the previous one, emerged timidly in the interviews.
[...] they [health professionals] give you a piece of paper, a referral, and when we arrive at the $P A C$, it has already received the advice that we had been there [at the Basic Healthcare Unit] and that there was no doctor [...] (S2).

It is understood that an organized health service, that aims to provide longitudinal and continuous care, does not involve only the participation of the person giving care, but of all those who think and practice healthcare. This comprehension of amplified health emerged among the spoken responses, because when pointing to the need for health professionals to perceive the children as human beings, the contribution of those who plan and organize the policies and plans of action in health was also brought into evidence. It emerged that, for Primary Healthcare to be the coordinating entity of healthcare, it is necessary to recognize the health needs in other health services, and integrate the actions carried out in those services to the care for users who are subscribed to the healthcare unit. Thus, it becomes necessary to understand that the coordination involves management of healthcare, so that there can be an attitude and practice of providing solutions in children's healthcare in Primary Healthcare.

[...] when a mother comes into a health unit, everyone should remember that there is a child there, a life, a human being that needs help, but my complaint is more directed to the prefecture and not to the care given [slight smile] (S15).

\section{Discussion}

The families in this reality present themselves as dissatisfied with the care received and, because it does succeed in providing solutions, they seek care in urgency and emergency services, preventing care from being integrated and longitudinal, and contributing to the reductionist model focused on medicalization and the figure of the doctor.

Peoples' satisfaction and happiness represent the way in which patients expect health professionals to perform in accordance with their capacities and the way in which they make technologies available for the purpose of producing health solutions $s^{14}$. However, the great difficulty taking place on a day-to-day basis is the transformation of the present hegemonic centralized health model into the biological approach which will result from the conversion of work practices and participation of the professionals in the health system ${ }^{15}$. 
In the health system one sees various different health units providing divergent results, although they have the same quantity of human and financial resources. The result is defined in accordance with how these resources are organized and deployed ${ }^{7,15}$. In this study divergences were found in aspects including: scheduling of medical consultations and return visits; itineraries for simple and complex medical tests; and waiting time for consultations.

Families need to be accepted and welcomed so that they do not feel unsupported when their children get ill. But the way in which technological arrangements have shaped the reality of the health services has tended to dispense with the context of a more wide-ranging clinical approach, separating the moment of actual giving of care to the child, with social as well as other consequences $^{14}$.

Welcoming and acceptance is the key point for organizing the points of entry to the health services, since it can integrate spontaneous demands and program actions, based on social determinants and technological arrangements ${ }^{7,16}$, without allowing the technological factors to become the central axis of the care given ${ }^{14,16,17}$.

The proposal to which we refer involves the organization of the health system into care networks, in which its services are coordinated by the Primary Healthcare units, in which the Healthcare Networks (Redes de Atenção a Saúde - RASs) are built on an interdisciplinary model, articulating the relationships between populations distributed by risks, healthcare focus or health actions, defined by the integrated view of health, by demographic or epidemiological situations, and by social determinants present in each society at a given time ${ }^{17,18}$. Under this situation, it might be possible for families using the health services, organized by the RASs, to find happiness, and an attitude and practice of solutions.

Based on the elements of integrated healthcare, such a situation would promise plasticity, that is to say, transformation in the health organizations and work processes, and also provide the 'otherness', interaction and movement in the construction of children's care ${ }^{8}$. Rebuilding health care requires thinking - following its having been de-characterized by fragmented and individualized actions over the course of time ${ }^{14}$.

In this respect, receptiveness by the healthcare service will be understood as an instrument for taking care, contributing to reorganization of work processes and expansion of the capacity and intention in favor of providing real solu- tions ${ }^{19}$. Added to this receptiveness is the concept of complete care $^{16}$ - providing a foundation for consolidating efforts toward practicable equitable actions by the health services.

This survey has found that coordination of the Primary Healthcare Services (APS) is fragile, and this has effects and consequences in terms of the capacity to provide solutions in children's healthcare - demonstrated by innumerable functional barriers that prevent families' access to the health services. These services also include the arsenal of technologies and, according to literature, technologies are important coadjuvant factors for providing solutions in primary healthcare ${ }^{19}$. In this study, the technologies highlighted were: medical tests of low and high complexity, specialized consultations, absence of acceptance for care, and the technical and scientific knowledge of the professional.

The availability only of hard technologies ${ }^{20}$ prevents families from achieving solutions to the children's health problems, since if the medical professional, for example, succeeds in taking the appropriate clinical approach, the other members of the interdisciplinary team could welcome the patient; listen; make referrals, and many problems would be resolved by the Primary Healthcare system.

The shortage of coordination resulted in absence of a culture of solutions, and caused families, although lacking financial resources, to take on the burden of seeking attention from independent supplementary health services providing the technology that they needed ${ }^{20}$. For this purpose, the focus for attention should be the family and the community, based on a central concept of promoting interrelationship between the services ${ }^{3,6,7,16}$, including the social determinants, which in this case means the social condition for living or working ${ }^{17}$. For interrelationship to be caused to work, communication is necessary, and it should be between professionals, sectors and users.

Communication is not restricted to transmitting and receiving messages; it involves people living, working and getting on together, relationship, connection and a longitudinal approach $^{6,16,21}$. Its absence, between professionals, services and families, showed that the Primary Healthcare services in this reality are fragile in relation to coordination, as well as deficient in the longitudinal aspect - which requires calls for a link to the population, in an environment of trust over time ${ }^{22}$.

Although we have Primary Healthcare services that are vulnerable and limited in terms of 
any culture and practice of providing solutions, the shortcomings in relation to coordination went beyond these concepts, because though faced with the need for referrals, safe public transport was not offered, and serious situations were described in the survey. The reports showed two factors that are essential for safety and continuity of care $^{3}$ were seen to be absent: communication, and medical transport.

No less importantly, the lack of referrals and counter-referrals also showed the absence of articulation between the services, one of the functions of coordination that tends to erode the capacity and achievability of solutions ${ }^{17,18}$. Due to the inefficiency of the services related to this group of subjects, families had to seek healthcare individually in urgent and emergency services in an attempt to solve their problems, generating a colossal demand for those services and dissatisfaction with the attention received. According to the literature ${ }^{6}$, medical transport systems and processes of referral and counter-referral require planning, movement and interaction between the public health services that exist.

Finally, the subject of management in healthcare drew attention to the strong approximation between thinking about and practicing health through innovative practices, work policies and collective $\operatorname{care}^{23}$. It is not enough that there are professionals engaged in individual actions seeking technical success unless there is desire, a plan, plasticity, movement and interaction of health managers, nor is it sufficient that there should be significant models for healthcare without plasticity, movement, otherness, interaction, temporality, responsibility and non-causality in care ${ }^{8,14}$.

The concrete nature of these elements in thinking about and in the practice of health gives an idea of the potential for practical success in health actions - indication that it is possible to abandon the biomedical model, achieve coordination in Primary Healthcare, and with it success of services in a solutions-oriented culture in children's healthcare ${ }^{14}$.

\section{Conclusion}

The results of this survey show the fragility of coordination, at the present time, in Brazilian Primary Healthcare, which results in children's healthcare, in the perception of parents and caregivers, not being centered on, nor achieving, solutions.
Coordination involves and includes articulation between health services and practices, with the aim of serving a diversity of objectives that are common to the community. Primary Healthcare should be capable of including all care that the user receives at various points of healthcare provision. Thus, communication is essential, as is also access to the technologies, systems of reference and counter-reference and safe transport, so as to organize the services in such a way that they do not leave families unsupported when their children become ill.

Thus the way forward that is suggested is: Implementation, consolidation and expansion of the Family Health Strategy (Estratégia Familiar de Saúde, or ESF), on the foundation of the RASs. This proposal emphasizes that Primary Healthcare actions reduce the demand for urgent and emergency services, and at the same time lead to a wider concentration on, and capacity for, solutions in those services.

It is emphasized that this survey reports the perception of caregivers for children less than one year old in relation to healthcare of the child in the Primary Healthcare services. This could be a limiting aspect for comprehension of the complexity of the subject. The study should be broadened, and through triangulation of data a vision should be obtained from the same point of view from professionals and managers of the health services.

\section{Collaborations}

RMM Silva Viera and CS participated in: a) conception, design, analysis and interpretation of data, b) drafting the article and revising it critically, and c) approval of the version to be published; BRGO Toso, ET Neves and Silva Sobrinho-RA participated in: b) drafting the article and revising it critically, and c) approval of the version to be published. 


\section{References}

1. Brasil. Ministério da Saúde (MS). Manual de vigilância do óbito infantil e fetal e do comitê de prevenção do óbito infantil e fetal. $2^{\mathrm{a}}$ ed. Brasília: MS; 2009.

2. Fundo das Nações Unidas para a Infância (Unicef). Committing to child survival: a promise renewed. New York: Unicef; 2012.

3. Mendes EV. O cuidado das condições crônicas na atenção primária à saúde: o imperativo da consolidação da estratégia da saúde da família. Brasília: Organização Pan-Americana de Saúde (OPAS); 2012.

4. Santos HG, Andrade SM, Silva AMR, Mathias TAF, Ferrari LL, Mesas AE. Mortes infantis evitáveis por intervenções do Sistema Único de Saúde: comparação de duas coortes de nascimentos. Cien Saude Colet 2014; 19(3):907-916.

5. Oliveira BRG, Viera CS, Collet N, Lima RAG. Causas de hospitalização no SUS de crianças de zero a quatro anos no Brasil. Rev Bras Epidemiol 2010; 13(2):268-277.

6. Starfield B. Atenção primária: equilíbrio entre necessidades de saúde, serviços e tecnologia. Brasília: Unesco, Ministério da Saúde (MS); 2002.

7. Mesquita Filho M, Luz BSR, Araújo CS. A Atenção Primária à Saúde e seus atributos: a situação das crianças menores de dois anos segundo suas cuidadoras. Cien Saude Colet 2014; 19(7):2033-2046.

8. Ayres JRCM. Cuidado e reconstrução das práticas de Saúde. Interface (Botucatu) 2003/2004; 8(14):73-92.

9. Ayres JRCM. Hermenêutica e humanização das práticas de saúde. Cien Saude Colet 2005; 10(3):549-560.

10. Streubert HJ, Carpenter DR. Phenomenology as method. In: Streubert HJ, Carpenter DR, editors. Qualitative research in nursing: Advancing the humanistic imperative. $5^{\text {th }}$ ed. Lippincott: Willians \& Wilkins; 2011. p. $72-95$.

11. Gadamer H. Verdade e método: traços fundamentais de uma hermenêutica filosófica. 9a ed. Petrópolis: Vozes; 2008.

12. Minayo MCS. O desafio do conhecimento. Pesquisa qualitativa em saúde. $11^{\mathrm{a}}$ ed. São Paulo, Rio de Janeiro: Hucitec, Fiocruz; 2008.

13. Brasil. Ministério da Saúde (MS). Conselho Nacional de Saúde. Resolução no 466, de 12 de dezembro de 2012. Diário Oficial da União 2013; 13 jun.

14. Ayres JRCM. Organização das Ações de Atenção à Saúde: modelos e práticas. Saude Soc 2009; 18(Supl. 2):1123.

15. Carvalho SR, Cunha GT. A gestão da atenção na saúde: elementos para se pensar a mudança da organização na saúde. In: Campos GWS, Minayo MCS, Akerman M, Junior MD, Carvalho YM, organizadores. Tratado de saúde coletiva. São Paulo, Rio de Janeiro: Hucitec, Fiocruz; 2007. p. 837-868.
16. Almeida PF, Giovanella L, Mendonça MHM, Escorel S. Desafios à coordenação dos cuidados em saúde: estratégias de integração entre níveis assistenciais em grandes centros urbanos. Cad Saude Publica 2010; 26(2):286-298.

17. Escorel S, Giovanella L, Mendonça MHM, Senna MC. O Programa de Saúde da Família e a construção de um novo modelo para a atenção básica no Brasil. Rev Panamericana de Salud Publica 2007; 21(2):164-176.

18. Brasil. Ministério da Saúde (MS). Portaria no 4.279 de 30 de dezembro de 2010. Institui as Redes de Atenção a Saúde (RAS). Diário Oficial da União 2010; $31 \mathrm{dez}$.

19. Almeida PF, Fausto MCR, Giovanella L. Fortalecimento da atenção primária à saúde: estratégia para potencializar a coordenação dos cuidados. Rev Panamericana de Salud Publica 2011; 29(2):84-95.

20. Merhy EE. Gestão da produção do cuidado e clínica do corpo sem órgãos: novos componentes dos processos de produção do cuidado em saúde. [on-line]. 2007. [15 telas]. [acessado 2012 ago 24]. Disponível em: http:// www.uff.br/saudecoletiva/professores/merhy/artigos -25.pdf

21. Araújo TCCF. Comunicação em saúde: contribuições do enfoque observacional para pesquisa e atuação. Arq Bras Psicol 2009; 61(2):1-13.

22. Silva JM, Caldeira AP. Modelo assistencial e indicadores de qualidade da assistência: percepção dos profissionais da atenção primária à saúde. Cad Saude Publica 2010; 26(6):1187-1193.

23. Carácio FCC, Conterno LO, Oliveira MAC, Oliveira $\mathrm{ACH}$, Marin MJS, Braccialli LAD. A experiência de uma instituição pública na formação o profissional de saúde para atuação em atenção primária. Cien Saude Colet 2014; 19(7):2133-2142.

Article submitted 03/07/2014

Approved 11/01/2014

Final version submitted 10/04/2014 